\title{
Estrogen Receptors, Progesterone Receptors and their Correlation with respect to HER-2/neu Status, Histological Grade, Size of Lesion, Lymph node Metastasis, Lymphovascular Involvement and Age in Breast Cancer patients in a hospital in north India
}

\author{
Mushood G. Nabi', Andleeb Ahangar' ${ }^{2}$, Subiya Kaneez ${ }^{3}$ \\ ${ }^{1}$ Assistant Professor, Department of Radiotherapy, Government Medical College Srinagar, Kashmir, India, ${ }^{2}$ Senior Resident, Department of \\ Ophthalmology, Government Medical College, Srinagar, Kashmir, India, ${ }^{3}$ Lecturer, Department of Radiotherapy, Government Medical College, \\ Srinagar, Kashmir, India
}

A B S TR A C T

Background: Breast cancer is the second most common cancer overall $(1.4$ million cases, $10.9 \%$ )and ranks 5 th as cause of death $(458,000.6 .1 \%)$. The present study was aimed to find the pattern of expression of ER, PR, HER-2/neu and to correlate ER, PR status with respect to various clinicopathlogical factors like HER-2/neu over expression, histological grade, tumor size, lymphnode metastasis, lymphovascular invasion and age of the patient. Materials and Methods: Data from 139 patients was collected and correlation of ER, PR status with various clinicopathological factors was analysed. Results: Mean age at diagnosis was 48.5 years, $56.8 \%$ cases being $\leq 50$ years of age. Tumor size ranged from 1 to $12 \mathrm{~cm}$. Most lesions $(57.5 \%)$ were $>2$ to $5 \mathrm{~cm}$ in size. The predominant morphology was Infiltrating Duct carcinoma-NOS (90.6\%). Majority of cases presented as grade II(46.7\%)lesions and lymph node involvement was seen in $66.9 \% .49 .6 \%$ cases were ER+, $49.6 \%$ cases were PR + , and HER-2/neu was positive $(3+$ ) in $15.8 \%$ cases. Older patients were mostly $\mathrm{ER}+\mathrm{PR}+$. Low grade tumors were mostly $\mathrm{ER}+\mathrm{PR}+$ as compared to high grade tumors. HER-2/neu status revealed an inverse association with hormone receptor positivity. No correlation was found between hormone receptor positivity and lymph node metastasis. Lymphovascular involvement was noted more in hormone negative ER-PR- tumors. Conclusion: ER and PR expression in our patients was found to be comparable to the studies done in Indian subcontinent, but lower than studies done in west, but triple negative breast cancer prevalence was relatively higher in our study $(34.5 \%)$.

Access this article online Website:

http://nepjol.info/index.php/AJMS DOI: http://dx.doi.org/10.3126/ ajms.v7i3.13563 E-ISSN: 2091-0576 P-ISSN: 2467-9100

Key words: Breast carcinoma, Estrogen Receptors (ER), Progesterone receptors (PR),

HER-2/neu, triple negative breast cancer

\section{INTRODUCTION}

It is estimated that 12.7 million new cancer cases and 7.6 million cancer deaths occurred in 2008 world wide. Lung cancer remained the most common cancer in the world both in terms of cases (1.6 million cases, $12.7 \%$ of total)and deaths (1.4 million deaths and 18.2\%). Breast cancer is the second most common cancer overall (1.4million cases, $10.9 \%)$ but ranks 5 th as the cause of death $(458,000,6.1 \%)$. Cancers of the Lung, stomach and liver predominate among males in developing regions ( $42 \%$ of new cancer cases, $48 \%$ of the total cancer deaths), while as breast and cervical cancers represent $33 \%$ of the new cancer cases in females, but only $25 \%$ of the corresponding cancer deaths. Incidence rate varies from 19.3 per 100,000 women in Eastern Africa to 89.9 per 100,000 women in 
Western Europe, and is high (greater than 80/100,000) in developed regions of the world (except Japan) and low (less than 40/100,000)in most of the developing regions. The range of mortality rates is less (approximately 6-19/100,000)because of the more favorable survival of breast cancer in (high incidence) developed regions. As a result, breast cancer ranks as 5 th cause of death from cancer overall (458,000 deaths), but it is still the most frequent cause of cancer death in women in both developing (269,000 deaths, $12.7 \%$ of total) and developed regions. ${ }^{1}$

India is a subcontinent with wide ethnic, cultural, religious and economic diversity. With rising incidence and awareness breast cancer is the commonest cancer in urban Indian females and the second commonest in the rural Indian women. As per the ICMR-PBCR data, breast cancer is the commonest cancer among women in urban registries of Delhi, Mumbai, Ahmadabad, Calcutta, and Trivandrum where it constitutes $>30 \%$ of all cancers in females. In the rural PBCR of Barshi, breast cancer is the second commonest cancer in women after cancer of the uterine cervix. $^{2}$

Breast cancer is a biologically heterogeneous disease and patients with the same diagnostic and clinical prognostic profiles can have markedly different clinical outcomes. ${ }^{3}$ Breast cancer survival is linked to early detection, timely appropriate treatment and genetic predisposition. Prognosis and management of breast cancer are influenced by many clinical, pathologic and molecular features which include, histopathologic type, grade of tumor, size of tumor, lymph node metastasis, Estrogen receptor ER status, Progesterone receptor PR status and C -erbB2 (HER-2) status of the tumor. ${ }^{4,5}$ In the present times determination of hormone status on biopsy specimen is advocated as standard practice.

Estrogen is an important mitogen exerting its activity by binding to its receptor(ER)and found in $50-80 \%$ of breast cancers. ${ }^{5}$ Endocrine treatments are assigned to antagonize the effects of estrogen. The presence of hormone receptors (ER \& PR) in the tumor tissue correlates well with the response to hormone therapy and chemotherapy. ${ }^{6}$ Progesterone receptor PR is expressed in $60-70 \%$ invasive breast carcinomas with a higher positivity in older age and post menopausal women. Loss of PR by tumor cells is associated with a worse prognosis. ${ }^{5,7}$ Patients with large tumors, poorly differentiated morphology, increased number of axillary lymph node metastasis and higher stage tumors have more chances of an ER \& PR negative status.., 8 Expression of ER and/or PR generally is associated with a better outcome. Survival and response to hormone therapy are most favorable among women with tumors positive for both ER and PR, intermediate for tumors discordant on receptor status and least favorable for tumors negative for both. ${ }^{4}$

HER-2/neu also known as C-erbB-2 is a proto-oncogene located on chromosome 17. It is amplified and the protein (HER -2) over expressed in 15-25\% of invasive breast carcinomas with associated poor prognosis. Over expression of HER-2/neu is a good predictor of response to transtuzumab (herceptin), but not a positive predictor of response to chemotherapy or overall survival. ${ }^{5}$

Studies have shown that in contrast to the western literature, percentage of estrogen and progesterone receptor (ER and $\mathrm{PR}$ ) positive tumors in Indian subcontinent is persistently low. ${ }^{9}$ The present study was undertaken to observe the trend and to analyze the status of hormone receptor expression in breast cancer at our institution and to assess their value in terms of established prognostic markers like size of tumor, grade of tumor, lymphovascular infiltraton, HER-2/neu status, and lymph node metastasis.

\section{MATERIALS AND METHODS}

A total of 139 patients were enrolled for the present study. The study was approved by the hospital ethics committee. All the operated cases of cancer breast who were referred/ visited our department from January 2009 to December 2012 for adjuvant treatment were enrolled in the study. Patients were registered in the Department of radiation oncology and a radiotherapy file for each patient was maintained. Informed consent was taken from all patients. The relevant information including, details about pre-surgical investigations, surgical details, investigations of metastatic work up, post operative complete histopathological details like type, modified Bloom Richardson grade, lymph node involvement, lymphovascular status, Estrogen receptors ER, Progesterone receptors PR status, HER-2/neu and other relevant investigations were noted in the proforma.

Patients with histopathology showing benign tumors, incomplete histopathological details, incomplete surgical details and those patients in whom no/incomplete information about ER, PR, and HER-2/neu status was available were excluded from the present study. Data of all patients was compiled and assessed for:

-The pattern of expression of ER/PR $\{\mathrm{ER}+, \mathrm{PR}+, \mathrm{ER}-$, PR- $\}$ and HER-2/neu in invasive breast cancer in patients visiting our institution.

-Correlation of ER, PR status with respect to HER2/ neu over expression, modified Bloom Richardson grade of tumor, size of tumor, lymph node metastasis, lymphovascular invasion and age was done. 
The Estrogen receptor ER and Progesterone receptor PR were interpreted on immunohistochemistry as positive when at least $1 \%$ of the tumor cells showed positive nuclear staining. HER-2/neu score of $3+$ was taken as positive by immunohostochemistry method. For equivocal results $(2+)$, ISH (in situ hybridization) tests were advised.

\section{RESULTS}

After proper scrutiny, a total of 139 cases were included in the present study. Table 1 shows the age distribution of patients. Mean age at presentation was 48.5 years. The youngest patient was 23 years old and the oldest patient was 75 years of age at the time of diagnosis. Majority of the cases $79(56.8 \%)$ were $\leq 50$ years of age. One hundred thirty six $(97.8 \%)$ cases presented in female breast whereas only $3(2.1 \%)$ cases were found in male breast.

In our study $97.84 \%$ cases were married where as $2.1 \%$ cases who presented to our hospital for adjuvant treatment were unmarried. Left breast was more commonly involved i.e. $75(53.9 \%)$ whereas right breast was involved in 64 $(46 \%)$ cases. Quadrant involvement in left breast was: Upper outer $52 \%$, upper inner $14.6 \%$, lower outer $14.6 \%$, lower inner $8 \%$, central $8 \%$ and $2.6 \%$ cases had more than one quadrant involvement in left breast where as quadrant involvement in right breast was: Upper outer $46.8 \%$, upper inner $15.6 \%$, lower outer $18.7 \%$, lower inner $4.6 \%$, central $9.3 \%$, and $4.6 \%$ cases had more than one quadrant involvement in right side.

Modified radical mastectomy was done in 104 (74.8\%) patients, $28(20.1 \%)$ cases had undergone conservative surgeries (lumpectomy with axillary clearance in $16(57.1 \%)$ cases, wide local excision with axillary clearance in $8(28.5 \%)$ cases, quadrantectomy with axillary clearance in $4(14.2 \%)$ cases) whereas $7(5 \%)$ cases had undergone modified radical mastectomy with reconstruction of breast as well. Infiltrating ductal carcinoma (IDC)was the predominant morphological category with IDC NOS (Not otherwise specified) in $126(90.6 \%)$ cases. Four cases $(2.8 \%)$ had Infiltrating Lobular carcinoma, $2(1.4 \%)$ cases had invasive mucinous carcinoma, $2(1.4 \%)$ cases had IDC with mucinous features and $1(0.7 \%)$ case each of Invasive

\begin{tabular}{|c|c|}
\hline Age in years & No of cases (\%) \\
\hline $21-30$ & $9(6.47 \%)$ \\
\hline $31-40$ & $34(24.46)$ \\
\hline $41-50$ & $36(25.89)$ \\
\hline $51-60$ & 47 (33.81) \\
\hline $61-70$ & $11(7.91)$ \\
\hline $71-80$ & $2(1.43)$ \\
\hline Total & $139(100)$ \\
\hline
\end{tabular}

apocrine carcinoma, solid variant of papillary carcinoma, medullary carcinoma breast, invasive duct carcinoma with lobular pattern and neuroendocrine features, mixed special tubular cibriform and infiltrating duct carcinoma were seen.

Mean number of lymph nodes dissected out were 10.9, highest being 50 . Mean number of lymph nodes having metastasis were 4.0 lymph nodes. Ninety three $(66.9 \%)$ cases had axillary lymph node metastasis, where as in 46 (33\%) cases no lymph nodes were involved. 1-3 lymph nodes were involved in $50(35.97 \%)$ cases, $4-9$ nodes in $25(17.9 \%)$ cases and more than 9 nodes were involved in $18(12.9 \%)$ cases.

Mean size of tumor was $3.30 \mathrm{~cm}$ ranging from 1 to $12 \mathrm{~cm}$. $80(57.5 \%)$ patients had a tumor size of greater than $2 \mathrm{~cm}$ to $5 \mathrm{~cm}, 40(28.7 \%)$ cases had a tumor size of $\leq 2 \mathrm{~cm}$. Only $9(13.6 \%)$ cases had a tumor size of $>5 \mathrm{~cm}$. In our study $13(9.3 \%)$ cases had modified Scarff-Bloom-Richardson Grade I, 65 (46.7\%) cases had Grade II and 61 (43.8\%) cases had Grade III tumors on histopathology.

Hormone receptor status was divided into four groups $(\mathrm{ER}+\mathrm{PR}+),(\mathrm{ER}+\mathrm{PR}-),(\mathrm{ER}-\mathrm{PR}+)$, and (ER-PR-), Figure 1 shows the hormone receptor expression.

69 (49.6\%) cases were ER positive, 70 (50.3\%) cases were ER negative, where as $69(49.6 \%)$ cases were PR positive and $70(50.3 \%)$ cases were PR negative. Out of 139 patients in our study $22(15.8 \%)$ cases were HER $-2 /$ neu positive $(3+)$ whereas $117(84.1 \%)$ cases were negative. $8(5.7 \%)$ cases were ER+, PR + , HER-2/Neu positive ( $3+$ ), whereas $48(34.5 \%)$ cases were triple negative i.e. ER-, PR-, HER2/neu -ve. $51(36.6 \%)$ cases were ER+, PR+, HER-2/ neu- and $12(8.6 \%)$ cases were ER-, PR-, HER-2/neu +.

Among the triple negative breast cancer patients majority $23(47.9 \%)$ had grade 11 tumors followed by $22(45.8 \%)$ cases with grade 111 tumors. Only $3(6.2 \%)$ cases had grade 1 tumors. Among the triple negative breast cancer cases, infiltrating ductal carcinoma IDC (not otherwise specified) was the predominant histopathology type seen among $20(90.9 \%)$ cases with grade 111 tumors, $22(95.6 \%)$ cases with grade 11 tumors and in all $3(100 \%)$ cases with grade 1 tumors. 1(4.3\%) case with grade 11 triple negative breast cancer had infiltrating ductal carcinoma with mucinous features. Among triple negative breast cancer cases with grade 111 tumors, $1(4.5 \%)$ patient had histopathology of infiltrating lobular carcinoma whereas $1(4.5 \%)$ patient had infiltrating ductal carcinoma with lobular pattern and neuroendocrine features.

Lymphovascular invasion on histopathological examination was noted in $49(35.2 \%)$ cases only, of which $18(36.7 \%)$ 
cases were ER+PR+ and 24 (48.9\%) were ER-PR- tumors. In $64.7 \%$ cases no lymphovascular invasion was noted.

Correlation of ER and PR status with respect to age, HER2/neu, modified SBR grade, size of tumor, lymphovascular infiltration status and Lymph node involvement is given in Table 2.

\section{DISCUSSION}

As per World cancer report $2008,{ }^{10}$ in WHO South East Asia Region SEAO in which India comprises of $67 \%$ of total population of the region, it was estimated that there were 158, 9000 incident cases of cancer in year 2008 (758,000 in men and 831,000 in women)and 1072,000 deaths from cancer (approximately 557,000 in men and 515,000 in women). In men the commonest cancer was lung cancer. In females, cervix cancer and breast cancer were the commonest incident and fatal forms of cancer. Majority of Indian breast cancer patients self detect their disease when it is a palpable lump or when it has progressed to involve local skin and/or chest wall or has resulted in distant metastasis. Illiteracy, lack of awareness about the disease, inadequate diagnostic facilities in peripheral areas and financial constrains may be some of the reasons for delayed diagnosis of the disease. As a result, Indian breast cancer patients present with advanced disease stage and have numerous poor prognostic factors like large tumor, lymphnode metastasis and high pathological grade etc. ${ }^{2}$
A total of 139 patients were included in the present study. Modified radical mastectomy was the most common surgery done in $104(74.82 \%)$ cases. Conservative surgeries were done in $28(20.1 \%)$ cases of which $16(57.1 \%)$ had undergone lumpectomy with axillary clearance. Modified radical mastectomy with reconstruction of breast (TRAM flap) was done in $7(5 \%)$ cases. $2.1 \%$ of total cases in our study were males.

Mean age at presentation was 48.5 years with range varying from 23 to 75 years. 51 to 60 years was the most common age group (33.8\%) involved (Table 1) however majority, $56.8 \%$ cases were of $\leq 50$ of years of age at the time of diagnosis. Sofi $e t$ al $^{3}$ reported $59.1 \%$ cases $\leq 50$ years of age, whereas Pallavi Shrigondekar et al ${ }^{9}$ reported 57.65\% cases between 31 to 50 years age group.

Left breast was involved more commonly (53.9\%) than right breast (46\%), and upper outer quadrant involvement was more common. Similar findings were recorded by Sofi et al. ${ }^{3}$ Inleft breast $52 \%$ cases had upper and outer quadrant lesion, whereas in Right breast $46.87 \%$ cases had upper and outer quadrant lesion.

Mean size of the lesion was $3.3 \mathrm{~cm}$. Majority of our cases $(57.5 \%)$ had tumor size of $>2$ to $5 \mathrm{~cm}$. Studies by Suvarchala SB et al, ${ }^{4}$ Pallavi Shrigondekar et al ${ }^{9}$ and Sofi et $a l^{3}$ also recorded majority of patients presenting with tumor size of 2 to $5 \mathrm{~cm}$. 19 (13.6\%) cases had tumor size of greater than $5 \mathrm{~cm}$ at presentation as compared to study

\begin{tabular}{|c|c|c|c|c|c|}
\hline Parameters & ER+PR+ (\%) & ER+PR- (\%) & ER-PR+ (\%) & ER-PR- (\%) & Total \\
\hline \multicolumn{6}{|l|}{ Age } \\
\hline$\leq 40$ & $16(37.2)$ & $3(6.9)$ & $4(9.3)$ & $20(46.5)$ & 43 \\
\hline $41-50$ & $16(44.4)$ & $2(5.5)$ & $2(5.5)$ & $16(44.4)$ & 36 \\
\hline$\geq 50-80$ & $27(45)$ & $5(8.3)$ & $4(6.6)$ & $24(40)$ & 60 \\
\hline \multicolumn{6}{|l|}{ HER-2/neu } \\
\hline Positive & $8(36.3)$ & $1(4.5)$ & $1(4.5)$ & $12(54.5)$ & 22 \\
\hline Negative & $51(43.5)$ & $9(7.6)$ & $9(7.6)$ & $48(41)$ & 117 \\
\hline \multicolumn{6}{|c|}{ Grade of tumor } \\
\hline 1 & $8(61.5)$ & $1(7.6)$ & $1(7.6)$ & $3(23)$ & 13 \\
\hline II & $30(46.1)$ & $5(7.6)$ & $3(4.6)$ & 27 (41.5) & 65 \\
\hline III & $21(34.4)$ & $4(6.5)$ & $6(9.8)$ & $30(49.1)$ & 61 \\
\hline \multicolumn{6}{|l|}{ Size } \\
\hline$\leq 2 \mathrm{cms}$ & $18(45)$ & $5(12.5)$ & $3(7.5)$ & $14(35)$ & 40 \\
\hline$>2-5$ & $34(42.5)$ & $3(3.7)$ & $6(7.5)$ & $37(46.2)$ & 80 \\
\hline$>5 \mathrm{cms}$ & $7(36.8)$ & $2(10.5)$ & $1(5.2)$ & $9(47.3)$ & 19 \\
\hline \multicolumn{6}{|c|}{ Lymphovascular } \\
\hline Present & $18(36.7)$ & $3(6.1)$ & $4(8.1)$ & $24(48.9)$ & 49 \\
\hline \multicolumn{6}{|l|}{ Infilitration } \\
\hline Absent & $41(45.5)$ & $7(7.7)$ & $6(6.6)$ & $36(40)$ & 90 \\
\hline \multicolumn{6}{|l|}{ Lymphnode } \\
\hline 0 & $18(39.1)$ & $1(2.1)$ & $3(6.5)$ & $24(52.1)$ & 46 \\
\hline $1-3$ & $21(42)$ & $5(10)$ & $2(4)$ & $22(44)$ & 50 \\
\hline $4-9$ & $10(40)$ & $3(12)$ & $4(16)$ & $8(32)$ & 25 \\
\hline$>9$ & $10(55.5)$ & $1(5.5)$ & $1(5.5)$ & $6(33.3)$ & 18 \\
\hline Total & 59 (42.4) & $10(7.1)$ & $10(7.1)$ & $60(43.1)$ & 139 \\
\hline
\end{tabular}


by Adedayo $e t \mathrm{al}^{11}$ in which only $4.7 \%$ cases presented with lesions $>5 \mathrm{~cm} .{ }^{11}$ Tumor size correlated inversely with hormone receptor expression. Less than $2 \mathrm{~cm}$ tumors were predominantly $\mathrm{ER}+\mathrm{PR}+$, whereas $>5 \mathrm{~cm}$ tumors were predominantly ER-PR-.

Infiltrating Ductal carcinoma (IDC) was the predominant histopathology with IDC NOS (not otherwise specified)in $126(90.6 \%)$ cases. Infiltrating Duct carcinoma NOS was also the predominant histopathology in studies by Aziz un Nisa et al ${ }^{5}(85.8 \%)$, Sofi et al ${ }^{3}(80.30 \%)$, Pallavi Shrigondekar et $a l^{9}(93.2 \%)$, Suvarchala S B et al $(93.7 \%)$ and Bhagat Vasudha $\mathrm{M}$ et al ${ }^{12}(94.8 \%)$.

In our study majority 65(46.7\%) cases had modified SBR grade II tumor followed by $61(43.8 \%)$ cases with grade III tumor and only $13(9.3 \%)$ cases had Grade I tumor. Studies by Suvarchala S B et al, ${ }^{4}$ Sofi et al, ${ }^{3}$ Bhagat Vasudha M et $a l^{12}$ and Pathak T B et al ${ }^{13}$ also recorded Grade II as the predominant Grade in $42.1 \%, 52.1 \%, 43.1 \%$ and $59 \%$ cases respectively. Pallavi Shrigondekar et $a l^{9}$ reported Grade III tumour as the commonest type. Grade of the tumor correlated inversely with the hormone receptor positivity. Grade I tumors were predominantly $\mathrm{ER}+\mathrm{PR}+$, whereas Grade III tumors were predominantly ER-PR-.

Expression of ER and/or PR generally is associated with a better outcome. ${ }^{4}$ Adjuvant hormonal therapy should be given to women whose breast tumor contains hormone receptor proteins regardless of age, menopausal status, involvement of axillary lymph nodes or tumor size. ${ }^{9}$ The prevalence of hormone receptor positive breast cancer in Asian countries has been found to be lower than in western world where more than $50 \%$ tumors express hormone receptors, however number of studies performed on this topic is much less in Asian communities as compared to the western world. ' In western studies ER is expressed in $70-90 \%$ of invasive lobular carcinoma and in $70-80 \%$ of invasive ductal carcinoma, and PR is expressed in $60-70 \%$ of invasive breast carcinomas. ${ }^{14-16}$ Sastre- Garaux et al ${ }^{15}$ found a positive expression of estrogen receptors more frequently in infiltrating lobular carcinoma ILC (79\%)and in mixed infiltrating lobular and infiltrating duct carcinoma ILC/IDC (83\%) than in non lobular infiltrative carcinomas NLIC $(72 \%)$. For progesterone receptors a positive expression was found in $63 \%$ of infiltrative lobular carcinoma ILC and of NLIC non lobular infiltrative carcinomas and in $69 \%$ of ILC/IDC (NOS). Zafrani $e t$ al ${ }^{16}$ found ER to be expressed in $81 \%$ of cases by immunohistochemistry in a prospective series of 793 infiltrating breast cancer patients. Christopher L Li et al ${ }^{17}$ found that from 1992 to 1998 the overall proportion of breast cancers that were ER+ and PR+ increased from $75.4 \%$ to $77.5 \%$ and from $65.0 \%$ to $67.7 \%$ respectively. These increases were limited to women of 40 to 69 years of age.

In our study $69(49.6 \%)$ cases were ER+, $70(50.3 \%)$ cases were ER-, $69(49.6 \%)$ cases were PR+ and $70(50.3 \%)$ cases were PR-. 59 (42.4\%) cases were both ER+PR+, whereas $60(43.1 \%)$ cases ER-PR-, $10(7.1 \%)$ cases were ER-PR+, and ER+PR- respectively (Figure 1). Our results are comparable to results obtained by Pallavi Shrigondekar et $a l^{9}$ where $45.95 \%$ cases were ER+ and an equal number of cases were $\mathrm{PR}+, 40 \%$ cases were $\mathrm{ER}+\mathrm{PR}+$ and $48.2 \%$ cases were both ER-PR-, and Mudduwa et $\mathrm{al}^{18}$ who recorded $45.7 \% \mathrm{ER}+$ and $48.3 \% \mathrm{PR}+$ tumors in their study. Suvarchala S B et al ${ }^{4}$ recorded ER+PR+ in $32.8 \%$ cases only and ER-PR- in $42.1 \%$ cases, ER+PR- in $14.06 \%$ cases and ER-PR+ in $10.94 \%$ cases. Desai et al ${ }^{19}$ reported $\mathrm{ER}+$ in $32.6 \%, \mathrm{PR}+$ in $46.1 \%$, $\mathrm{ER}+\mathrm{PR}+$ in $25 \%, \mathrm{ER}+\mathrm{PR}-$ in $7.4 \%$, ER-PR+ in $21.1 \%$ and ER-PR- in $46.5 \%$ cases. Some studies like those by Pathak T B et al ${ }^{13}$ reported overall positivity for ER as low as $28 \%$ and for PR to be $19 \%$, whereas Aziz un nisa et al recorded ER and PR positive in $32.7 \%$ and $25.3 \%$ cases only. Using data from 11 population based cancer registries that participated in the SEER(surveillance,epidemiology and end results)programme in USA 155,175 women of at least 30 years of age with a primary diagnosis of invasive breast carcinoma, Lisa Dunnwald et a ${ }^{20}$ recorded ER $+\mathrm{PR}+$ in $63 \%$, ER+PR- in 13\%, ER-PR+ in 3\%, and ER-PR- in $21 \%$ cases.

C- erb-B2 is a proto-oncogene located on chromosome 17, it is amplified and/or the protein (HER -2)over expressed in $15-25 \%{ }^{14}$ of invasive breast carcinoma and is associated with poor clinical outcome. In our study C-erb over expression was seen in $22(15.8 \%)$ cases. Similar results were seen by Pallavi Shrigondekar et al ${ }^{9}$ who reported HER 2/ neu positive in $16.75 \%$ cases, Mudduwa et al ${ }^{18}$ reported

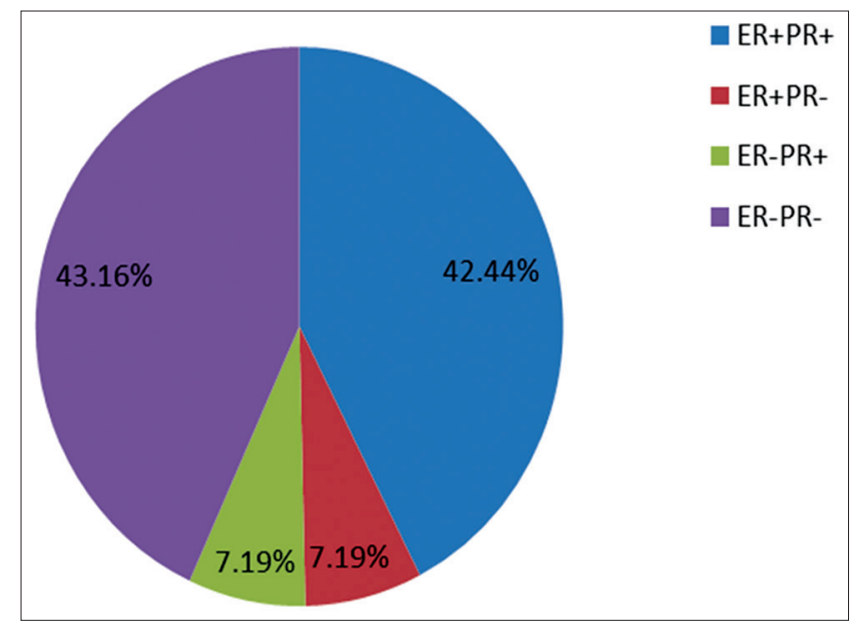

Figure 1: Hormone Receptor Expression 
19.1\% tumors being positive for HER 2/neu. Studies by Aziz un nisa $e t a l^{5}$ showed expression of HER 2/neu in $24.7 \%$ cases. In our studyHER-2/neu status revealed an inverse association with hormone receptor status.

Lymphovascular invasion was absent in 90 (64.7\%) cases. Only $49(35.2 \%)$ cases had tumors showing lymphovascular involvement on histology and of them majority $(48.9 \%)$ cases were hormone negative ERPR-tumors, where as lymphovascular invasion was found in $36.7 \%$ cases with ER+PR+ tumors. Our results are comparable to Pallavi Shrigondekar et $a l^{9}$ who recorded $52.5 \%$ cases with lymphovascular invasion in hormone negative ER-PR- tumors while as $37.2 \%$ cases with lymphovascular invasion were $\mathrm{ER}+\mathrm{PR}+$ tumors. In our study lymphovascular invasion was found more in hormone negative ER-PR- tumors. In our study axillary lymph node metastasis was recorded in $93(66.9 \%)$ cases. Our findings are comparable to studies by Vaidyanathan et $a^{21}$ who reported $59 \%$ lymph node involvement, Lakmini $\mathrm{K}$ B Muddawa $e t a l^{18}$ reported $57.6 \%$ and Aziz un nisa $e t a l^{5}$ reported $71.3 \%$ axillary lymph node involvement.

Thirty four point five percent patients in our study represented triple negative breast cancers TNBC (ER-,PR,HER 2/neu-)which is higher than normally reported in the literature (10-25\%). ${ }^{22}$ Our results are comparable to results by Aramita saha $e^{2} a^{23}$ from Kolkata, India who reported $30.6 \%$ cases as triple negative breast cancers. Other studies like Bhagat Vasudha et al, ${ }^{12}$ Patil et al, ${ }^{24} \mathrm{~S}$ Krishnamurthy et al ${ }^{22}$ reported $25.8 \%, 19.9 \%$, and $18.5 \%$ cases as triple negative breast cancers in their respective studies. Triple negative breast cancer is an aggressive phenotype affecting younger age group and has poor prognosis. Now a day's immunohistochemistry, microassay techniques, and cytogenetics are necessary for exact diagnosis, better prognostication and for application of newer modalities of treatment in breast cancer patients. ${ }^{22}$ By adding CK 5/6 and EGFR as the positive markers to the triple negative phenotype, a significantly worse outcome group can be identified among triple negative cases - the basal subtype. The basal phenotypes have more aggressive pathological features than the non-basal phenotypes. ${ }^{25}$

\section{CONCLUSION}

In our study majority $(56.8 \%)$ of patients were less than 50 years of age, older patients were more likely to be $\mathrm{ER}+\mathrm{PR}+$ than younger patients. Breast cancer was found in $3(2.1 \%)$ male patients.

HER 2/neu status revealed an inverse association with hormone receptor positivity. Low Grade tumors were mostly ER+PR+ as compared to Grade III tumors. Size of tumor correlated inversely with the hormone positivity. Small sized lesions were mostly $\mathrm{ER}+\mathrm{PR}+$, than large sized tumors. Lymphovascular involvement was more in hormone negative ER-PR- tumors, however there was no correlation between receptor positivity and lymph nodes with metastasis in our study. In our study ER and PR expression in invasive breast cancer patients was found to be comparable to the studies done in India/Asia, but lower than the studies done in West. Triple negative breast cancer prevalence in the study population was also higher (34.5\%)than normally reported in literature. More studies involving large sample size need to be done in this context more so in Asian countries.

\section{BIBILOGRAPHY}

1. Ferlay J, Shin HR, Bray F, Forman D, Mathers C, and Parkin DM. Estimates of world wide burden of cancer in 2008: GLOBOCAN 2008. Int J Cancer 2010;127:2893-2917.

2. Agarwal $G$ and Ramakant $P$. Breast cancer care in India: The current scenario and the challenges for the future. Breast Care2008;3:21-27.

3. Sofi GN, Nabi J, Nadeem R, Shiekh RY, Khan FA, Sofi AA, et al. Estrogen receptor and progesterone receptor status in breast cancer in relation to age, histological grade, size of lesion and lymph node involvement. Asian Pacific J Cancer Prev 2012;13:5047-5052.

4. Suvarchala SB, and Nageswararao R. Carcinoma BreastHistopathological and hormone receptors correlation. J Biosci Tech 2011;2:340-348.

5. Nisa A, Bhurgri Y, Raza F, and Kayani N. Comparison of ER, PR, and HER-2/neu(C-erb B 2)reactivity pattern with histologic grade, tumor size and lymph node status in breast cancer. Asian Pacific J Cancer Prev 2008;9:553-556.

6. Barnes DM and Hanby AM. Oestrogen and progesterone receptors in breast cancer: Past, present and future. Histopathology 2001;38:271-274.

7. Mc Gurie WL, and Clark GM. The prognostic role of progesterone receptors in human breast cancer. Semin Oncol 1983;10:2-6.

8. Fisher ER, Redmond CK, Liu H, Rockette H, and Fisher B. Correlation of estrogen receptor and pathologic characteristics of invasive breast cancer. Cancer 1980; 45:349-353.

9. Shrigondekar P, Desai S, Bhosale S, Mankar D and Badwe A. Study of hormone receptor status of breast carcinoma and its correlation with the established prognostic markers. International Journal of Health Sciences and Research 2012;1:109-116.

10. IARC. World Cancer Report 2008.wcr_2008.pdf (on-line). Available fromhttp//www.iarc.fr/en/publications/pdfs-online/ wcr/2008/wcr_2008.pdf. [18 Dec 2012, date last accessed].

11. Onitilo AA, Engel JM, Greenlee RT and Mukesh BN. Breast cancer subtypes based on ER/PR and HER-2/neu expression: Comparison of clinicopathological features and survival. Clin Med Res 2009;7:4-13.

12. Bhagat VM, Jha BM, and Patel PR. Correlation of hormonal receptor and HER-2/neu expression in breast cancer: A study at tertiary care hospital in south Gujarat. Natl J Med Res 2012;2:295-298.

13. Pathak TB, Bashyal R, Pun CB, Shreastha S, Bastola S, Neupane $S$, et al. Estrogen and Progesterone receptor 
expression in breast carcinoma. Journal of Pathology of Nepal 2011;1:100-103

14. Lal P, Tan LK and Chen B. Correlation of HER-2 status with estrogen and progesterone receptors and histologic features in 3655 invasive breast carcinomas. Am J Clin Pathol 2005; 123:541-546.

15. Sastre-GX, Jouve $M$, Asselain $B$, Vincent $S A$, Beuzeboc $P$, Dorval T, et al. Infiltrating lobular carcinoma of the breast; clinicopathologic analysis of 975 cases with reference to data on conservative therapy and metastatic patterns. Cancer 1996; 77:113-120.

16. Zafrani B, Aubriot MH, Mouret E, De Cremoux P, De Ryckey, Nicolas A, et al. High sensitivity and specificity of immunohistochemistry for the detection of hormone receptors in breast carcinoma: Comparison with biochemical determination in a prospective study of 793 cases. Histopathology 2000; 37:536-545.

17. Li CL, Darling JR and Malone KE. Incidence of breast cancer by hormone receptor status from 1992-1998. J Clin Oncol 2003; 21:28-34.

18. Mudduwa LKB. Quick score of hormone receptor status of breast carcinoma: Correlation with the other clinicopathological prognostic parameters. Indian J Pathol Microbiol 2009;52:159-163.
19. Desai SB, Moonim MT, Gill AK, Punia RS, Naresh KN and Chinoy RF. Hormone receptor status of breast cancer in India: A study of 798 Tumors. Breast 2000; 9:267-270.

20. Dunnwald LK, Rossing MA and Li CL. Hormone receptor status, tumor characteristics and prognosis: A prospective cohort of breast cancer patients. Breast Cancer Res 2007; 9:R6.

21. Vaidyanathan $K$, Kumar $P$, Reddy CO, Deshmane $V$, Somasundaram K and Mukherjee G. ErB-2 expression and its association with other biological parameters of breast cancer among Indian women. Indian J Cancer 2010;47:8-15.

22. Krishnamurthy $S$, Poornima R, Challa $V$ and Basavana Goud YG. Triple negative breast cancer- Our experience and review. Indian J Surg Oncol 2012;3:12-16.

23. Saha A, Chattopadhyay S, Azam M and Sur PK. Clinical outcome and pattern of recurrence in patients with Triple negative breast cancer as compared with non-Triple negative breast cancer group. Clinical Cancer Investigation Journal 2012; 1:201-205.

24. Patil VW, Singhai R, Patil AV and Gurav PD. Triple negative(ER, $\mathrm{PgR}, \mathrm{HER}-2 / \mathrm{neu})$ breast cancer in Indian women. Breast Cancer: Targets and Therapy 2011; 3:9-19.

25. Rao C, Shetty J and HL Krishan Prasad. Immunohistochemical profile and morphology in triple negative breast cancer. Journal of Clinical and Diagnostic Research 2013; 7:1361-1365.

Authors Contribution:

MGN - Concept and design of study, collected data, review of literature, manuscript preparation, analysis of data and results, prepared first draft of manuscript, critical revision of manuscript, manuscript editing; AA - Concept and design of study, review of literature, manuscript prepration, analysis of results, prepared first draft of manuscript, critical revision of manuscript, manuscript editing; SK - Collected data, review of literature.

Source of Support: Nil. Conflict of Interest: None. 